\title{
African Political Systems
}

\section{Professor Meyer Fortes writes:}

Your warm and appreciative obituary of Professor A. R. Radcliffe-Brown in the January I956 issue of Africa (vol. xxvi, no. i, p. 1) expresses the sense of loss felt by all students of African cultures and societies on his death. There is, however, one error of fact in your article which, I am sure, Professor Radcliffe-Brown would have wished to see corrected. You say: "He sponsored the preparation of African Political Systems, the first of the Institute's collective studies of a particular aspect of African social life. This volume, to which he contributed a valuable Preface, has become an established and widely used introduction to the subject.' In point of fact, Professor Radcliffe-Brown did not 'sponsor the preparation' of the book, nor, for that matter, did the International African Institute initiate its production. The facts are as follows.

In the spring of 1937 I was in Cape Town and there saw a good deal of Professor I. Schapera. He gave me the proofs of his forthcoming book, $A$ Handbook of Tswana Law and Custom, to read and I was thus stimulated to describe to him the strikingly different political and legal institutions of the Tallensi, among whom I had just been working. Out of these talks was born the idea of bringing out a comparative survey of African political institutions. On returning to England in the autumn of 1937 I approached Dr. Evans-Pritchard and proposed that he and I should jointly edit a book on the lines of African Political Systems. Fortunately he agreed, or else the book would never have been undertaken. He and I then drew up a list of possible contributors. We aimed partly at a wide 'coverage' but what we considered more important was to enlist the co-operation of professional social anthropologists with recent field experience in Africa and a known interest in the kind of problems we had in mind. It was not till this stage that we took counsel with Professor Radcliffe-Brown and were fortunate enough to receive from him a promise to contribute a Preface. He did not, in fact, write the Preface until he had the opportunity to read all the contributions in proof.

As regards the International African Institute, Evans-Pritchard and I put the proposal for the book to Sir Hanns Vischer and Professor D. Westermann because we felt that, as several of the prospective contributors were former or current Fellows of the Institute, the Institute should have the first refusal on the publication. I recollect discussing the proposal for the book at length with Professor Westermann, when he was in London in 1937, and of receiving from him a promise that he would persuade the Executive of the Institute to sponsor publication. As far as I know there was, at that time, no scheme for a series of 'collective studies' of 'aspects of African social life' to be brought out by the Institute.

Though Professor Radcliffe-Brown did not 'sponsor the preparation' of African Political Systems his Preface added immensely to the book's significance, and his willingness to contribute this Preface was an example of his unfailing helpfulness to younger scholars.

\section{Local Government in the Colonies $\mathrm{I}$}

A CONFERENCE on the development of local government in the colonies was held at Queens' College, Cambridge, from 22 August to 2 September 1959, under the chairmanship of Sir John Wrigley. It was arranged by the Royal Institute of Public Administration with the support and co-operation of the British Colonial Office, and was attended by some I 20 members of whom nearly 70 came from 23 colonial territories. Among those taking part were Ministers or senior officials responsible for local government in most of the larger territories,

1 Development of Local Government in the Colonies: Report of a Conference, Queens' College, Cambridge, 22 August-2 September 1955. Royal Institute of Public Administration,'Haldane House, $76 \mathrm{~A}$ New Cavendish Street, London, W. I. 
officers of the Colonial Office, and experts from local authorities and universities in Britain, and from Belgium, Canada, Eire, France, the Netherlands, and the United States.

The purpose of the conference was the study and discussion of local government problems, the pooling of experience, and the exchange of views on ways in which progress in the development of representative local government could best be furthered. Some territories, such as British Guiana, Jamaica, and parts of Africa, already possess long-established local authorities on the English pattern, but in the majority of African territories the forms of local government now being introduced are new, the result of a gradual transition, which is still going on, from a system of indirect rule to one of government by elected local authorities.

The conference divided into six study groups concerned with the following subjects: constitutional and political factors in the development of local government; relations of local authorities with the central government and with traditional authorities; financial resources of local authorities; problems of representation; internal organization and management; recruitment and training of staff. The studies undertaken thus covered both the kind of local government to be established and the action required to make it work. It was generally assumed that the development of local government will continue to be based largely on the English model, not only because of the long and intimate acquaintance of British administrators and expert advisers with that system and its problems, but also because it very often appears to be what the colonial peoples themselves want. Many of the problems encountered in the development of local government in England have already arisen in the colonial territories, but the methods of solving them must naturally differ, and account must be taken of varying conditions and relative stages of development as well as of special problems, such as those arising out of the complex social, racial or religious structure in certain territories. The conference felt strongly that the development of a sense of responsibility and disinterestedness was essential to the success of local government.

\section{International Institute of Differing Civilizations}

Trie twenty-ninth study session of INCIDI was held in London from 13 to 16 September 1955, Sir Nevile Butler, K.C.M.G., C.V.O., presiding. The international character of the activities of INCIDI was in evidence at this, as at its other sessions; representatives from Europe, Latin America, Indonesia, Pakistan, Africa, Israel, and the United States presented reports and participated actively in the discussions. The subject of this study session was 'The development of a middle class in tropical and sub-tropical countries'. The report of the session, which has now been published, gives the texts of the papers presented and a full summary of the discussions. In addition to reports concerned with specific areas--Latin America, Tunisia, Morocco, French Africa, Ceylon, Portuguese Africa, the Caribbean, Pakistan-general reports on the political, economic, and social aspects of the subject were read and discussed. The meaning of the term 'middle class' and the special qualities, status, and functions of a middle class in any society were discussed by many of the speakers. Mr. Henry Hopkinson, Minister of State for the British Colonies, in his opening address, suggested that the nature and character of a middle class were moulded by the historical circumstances in which it had emerged and that in Britain two formative influences had been the process of urbanization and industrialization, and the development of the educational system. The emergence of a middle class in other societies offered both contrasts and parallels. M. R. Millot, speaking of the evolution of the middle classes in Europe, suggested that there were at least three categories of persons who might be termed 'middle class', but that with changing social conditions other new categories appeared, while at the same time the 